\title{
Erratum to: Human Error, Safety and Systems Development
}

\author{
Philippe Palanque $^{1}$, Jean Vanderdonckt ${ }^{2}$, and Marco Winckler ${ }^{1}$ \\ 1 University Paul Sabatier, Institute of Research in Informatics of Toulouse (IRIT), \\ 118, Route de Narbonne, 31062 Toulouse Cedex 9, France \\ \{palanque, winckler\}@irit.fr \\ 2 Université Catholique de Louvain, Place des Doyens 1, \\ 1348, Louvain-La-Neuve, Belgium \\ jean.vanderdonckt@uclouvain. be
}

\section{Erratum to:}

P. Palanque, J. Vanderdonckt, and M. Winckler (Eds.)

Human Error, Safety and Systems Development DOI: $10.1007 / 978-3-642-11750-3$

The book was inadvertently published with an incorrect name of the copyright holder. The name of the copyright holder for this book is: (c) Springer-Verlag Berlin Heidelberg. The book has been updated with the changes.

The updated original online version for this book can be found at DOI: $10.1007 / 978-3-642-11750-3$

P. Palanque, J. Vanderdonckt, and M. Winckler (Eds.): HESSD 2009, LNCS 5962, p. E1, 2010.

(C) Springer-Verlag Berlin Heidelberg 2017 